\title{
Bosses matter: The effects of managers on workers' performance
}

\section{What evidence exists on whether bad bosses damage workers' performance, or good bosses enhance it?}

Keywords: managers, bosses, peers, productivity

\section{ELEVATOR PITCH}

A good boss can have a substantial positive effect on the productivity of a typical worker. While much has been written about the peer effects of working with good peers, the effects of working with good bosses appear much more substantial. A good boss can enhance the performance of their employees and can lower the quit rate. This may also be relevant in situations where it is challenging to employ incentive pay structures, such as when quality is difficult to observe. As such, firms should invest sufficiently in the hiring of good bosses with skills that are appropriate to their role.

\section{KEY FINDINGS}

Pros
$\oplus$ Economists now have good data to measure the
effects of bosses on workers' performance.
$\oplus$ Being assigned to a good boss increases personal
productivity relative to being assigned to a bad
boss and the effects are large.
$\oplus$ Good bosses have some universal traits: they
coach and teach and offer insight into the strategy
of the firm and the worker's career goals in light of
that strategy.
$\oplus$ The effects of good bosses dominate the effects of
good peers.
$\oplus$ Workers quit bad bosses and bad bosses are more
likely to leave the firm.

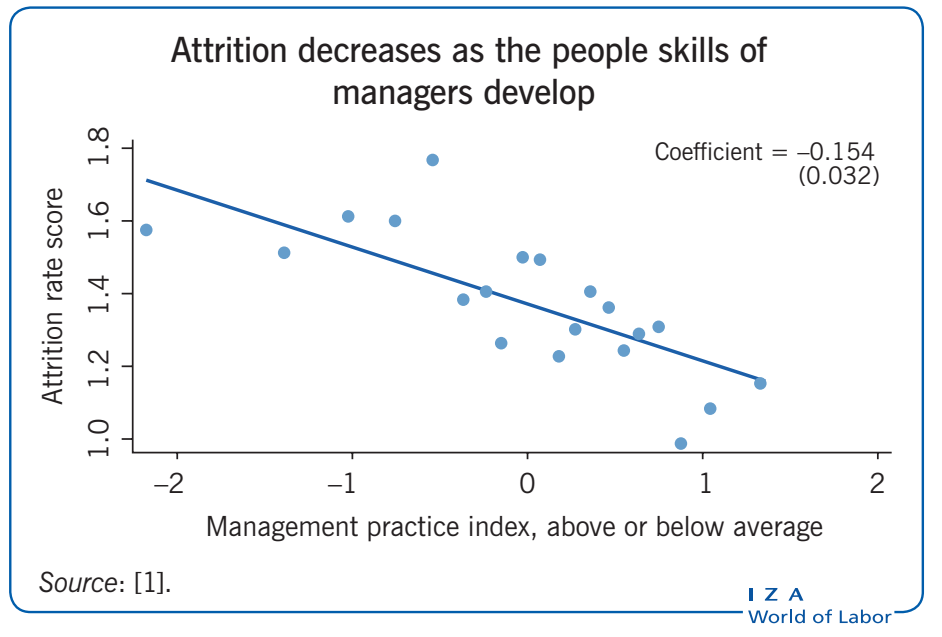

Cons

- Boss traits are not universal; a good boss at one firm might not be a good boss at another firm.

- Managerial talent is sometimes innate, at other times it is learned.

- Good bosses are good in part because they attract good workers.

\section{AUTHOR'S MAIN MESSAGE}

Firms make extensive investments in their employees. They invest in the hiring of workers that match the firm's needs, and they invest in workers' human capital once they are employed. New research suggests that the hiring and training of good bosses may carry substantial weight when it comes to workers' performance. Investing in a good boss has positive effects on the productivity of the workers he or she supervises, and on the retention of these workers. Hence, firms are now seeking to assess the effects that bosses have on their workers' performance, and to assess the traits of the bosses that have the most impact. 


\section{MOTIVATION}

Most workers have bosses. A boss is someone who manages the day-to-day workflow and activities of the workers they supervise. Most importantly, a boss is also someone who coaches and trains subordinates. Within manufacturing, first-line supervisors make up 10\% of the non-managerial workforce; that is, every ten workers have one boss. Within the retail trade, they make up $12 \%$ of the workforce. First-line supervisors constitute an occupational category in government statistics, e.g. the US Bureau of Labor Statistics (BLS).

Much has been done to measure the effects of CEOs or other high-level leaders on the performance of firms. These managers are natural targets for research because data are widely available for them and because they play important roles in managing firms and workers. But, there are far fewer high-level managers (like CEOs) than there are bosses, and the direct impact of CEOs on workers is likely less important.

Though past research literature has largely been silent on the effects of bosses, the press has been replete with musings on boss effects and traits. It is often said that workers do not leave bad firms, they leave bad bosses. New research asks, do good bosses elicit higher performance among workers, and lower quit rates? The answer is that good bosses indeed have both effects on their workers.

\section{DISCUSSION OF PROS AND CONS}

Economists are increasingly finding better data to measure the effects of bosses on workers' performance, as well as the sources of these effects. Firms are also increasingly doing so through their own People Analytics groups (groups within large firms that analyze data on employees and their performance).

A likely reason why there has been so little evidence on the role of bosses in the workplace is that, until recently, it has been very difficult to obtain data from firms that can be used to estimate the impact of bosses. There are a few key requirements in the data to estimate boss effects. First, productivity data on workers is needed, along with links to the identity of each worker's boss. Second, it is necessary that workers change bosses. It could be true that good bosses are assigned good workers. To control for this possibility, one must estimate a worker's baseline performance and then move the worker to another boss to estimate the boss effect. Furthermore, it is necessary that the data set is sufficiently large. The boss effect is based on evaluations of the job changers who join the boss's team; therefore, there must be a lot of job changers to produce a robust result.

Two recent studies make use of new data sources that allow for the estimation of boss effects. The first is a study of workers in a large US firm that performs technology based service (TBS) jobs [2]. The authors are not allowed to reveal the jobs that are done by the employees, but can reveal that individual productivity is measured by computers that record the start and finish times of each transaction. There are many examples of this type of work, including retail sales clerk jobs, airline reservation agent jobs, insurance claims adjuster jobs, call center jobs, and computer monitored data entry jobs. The company studied has 23,878 workers who are followed monthly from June 2006 through May 2010, for a total of 5.7 million observations. The observed workers have 1,940 bosses. Each worker stays for an average of two years and has an average of four bosses during that time. Workers change bosses often, so the "boss effect" on productivity is easily assessed. 
The second such study is on the management of new car salespeople [3]. This study follows an auto sales firm in Japan from December 1998 through November 2005; monthly data on profits by salesperson for 70 branches are available. Given 996 workers, there are 44,490 observations with 158 managers.

\section{Bosses matter}

The data requirements described above foreshadow the methods used to estimate boss effects. The key question posed is, what determines workers' productivity?

A worker's productivity on the job is determined by a set of factors: personal ability, learning over time, the quality of the current boss, the quality of the previous boss, whether the current boss is a good match for the worker, and the effects of peers. The econometric model used to estimate boss effects is conceptually a simple one, though difficult to estimate. Productivity is related to boss identifiers, person identifiers, the past boss, personal tenure, the match between the worker and boss, and the peer group.

What is striking is that boss quality strongly affects the worker's productivity. There is a very clear distribution of boss quality. Importantly, the impact on the worker of getting a top boss is considerable. In the study of TBS workers [2], the move from an average quality boss to one in the 90 th percentile raises worker productivity by six units per hour, on a mean productivity of ten units per hour. Thus, when workers move from an average boss to a high-quality boss, productivity could rise by $50 \%$.

A study of a large service sector firm in Scandinavia shows that there are high-ability managers who rate their own team members higher in personnel evaluations, partially because these managers are more lenient in evaluating than others, and partially because their team members become higher performers [4]. The study on retail car dealerships also finds large boss effects on productivity [3].

Economists who study managers typically examine the impact of top executives, because there are publicly available data sets on firms' performance and top executives from Compustat and Execucomp. A pioneering work from 2003 studies the impact of top executives on their firms' performance [5]. The authors use the data sets to follow 500 managers who move around within a group of 600 large firms from 1992 to 1999. The results show that top managers or executives matter: for a range of different dependent financial variables, top managers exert an economically meaningful impact on the firm.

While the 2003 study stands out for its careful estimation of manager effects [5], there is a massive literature on whether CEOs deserve the high pay that they earn, and whether they are paid for performance. The study on car dealerships suggests that top performing managers are rewarded with higher pay, but the variance in pay is considerably less than the variance in performance [3]. Overall, the literature on CEO compensation shows that only a portion of executive pay is related to performance.

The most prevalent past work by economists regarding bosses is on school principals [6] and sports teams' coaches [7]. Principals exert influence on students' test scores by hiring and motivating better teachers, or by firing poor teachers, and a school's improvement from a change in principal can be substantial. 


\section{What are the characteristics of good bosses?}

If some bosses are better than others, are there personal traits that are particularly possessed by good bosses? While the economics literature has only begun to answer this question, the business school literature has long considered it.

Economists identify two traits that improve boss quality. One is that good bosses are good teachers. In the study of TBS jobs, being assigned to a good boss has a reasonably long-term effect on performance [2]. After a worker leaves a good boss, the worker retains $25 \%$ of any performance gains for the next year of employment. The implication is that the good boss is either training the worker to do their job better or is motivating the worker in such a way that they permanently work harder (perhaps because the previous boss has instilled in the worker higher career aspirations). The second trait of good leaders is that they are experts in the work they are managing. A study from 2011 emphasizes that the best bosses are those who were experts in their field before they became bosses; they know how to be top performers [7]. Moreover, these experts are most likely teaching the skills that they themselves have mastered over time, thus combining both qualities. This is true of the literature on the effects of good coaches; they were star players before becoming great coaches.

If a boss's role is to teach, why are there so many bosses within firms? Specifically, why can't one great boss teach all workers (in a lecture setting) how to do their jobs? If the role of the boss is to inspire and lead, then the boss is a "public good," and one star boss should supervise all the workers in the firm. According to this line of reasoning, there should be no lower quality bosses in a firm. However, this type of view really applies to the CEO role, in which one person oversees an entire firm. As mentioned previously, the occupational distribution of workers in the BLS data shows that there is one boss for about every ten workers. Hence, one boss does not supervise all workers. The data used in the TBS study show that bosses spend about half their time teaching in a common setting and about half their time tutoring one-on-one [2]. Please note that this inference is based on the econometric estimation of boss effects: there are no direct data on the time allocation of bosses.

Firms have made considerable efforts exploring the optimal traits of bosses, and their results have been reported in the business school press. In 2009, Google decided it had a problem with its managers [8]. Google engineers did not want to be managed, yet upper-level management at Google suspected that managers mattered. Google undertook a study they labeled "Project Oxygen" to find out whether managers mattered, and if so, why. They used regression analysis to determine whether managers who scored high semi-annual performance evaluations had subordinate engineers who also scored highly on performance and retention. The answer was that they did. Google then conducted double-blind qualitative surveys of their best and worst managers, asking about the managers' day-to-day activities. They identified eight behaviors that stood out among the high-performing managers: good coach; empowers the team; expresses interest in employee well-being; is results-oriented; listens and shares information; helps with career development; has a clear vision for the team; has key technical skills.

A similar exercise was undertaken by The Royal Bank of Canada (RBC), which is the largest bank in Canada, with 80,000 employees. They identified a set of traits that they 
thought their lower-level managers should exhibit [9]. These traits are largely the same as those identified at Google: good managers should facilitate high performance via coaching, giving feedback, addressing obstacles, and setting directions. These traits were identified from qualitative evidence, but the question was whether they had any empirical impact? RBC concluded that they did. They showed first that employees who are more "engaged" in their work are more productive, with engagement being measured in an "Engagement Survey" about job satisfaction and the worker's views on the positive traits of his or her boss. RBC was also able to measure worker performance because their back-office operations have quantitative measures of performance. Therefore, they could show that engagement was correlated with performance. In particular, they showed that positive boss traits are found for bosses when workers are most engaged. (Many firms have now adopted such "Engagement Surveys" and are therefore measuring boss quality as perceived by employees.)

These results give rise to the question of whether good boss traits can be taught, or whether they are innate traits that should be identified when bosses are hired. Rephrasing this issue: are good bosses characterized by good traits (that may be innate) or good practices or activities (that can be learned)? The proliferation of business schools over the last 50 years certainly suggests that managerial practices can be taught. After Google determined which traits mattered, it put in place a program to teach good managerial behaviors and to reward them [8]. By late 2012, Google could show that their training programs had improved workers' performance. RBC also put in place training programs to improve managerial skills. However, in both cases, not all managers could improve performance; Google even demoted some poor performing managers. So, in conclusion, managers do need to be hired or promoted carefully for their managerial skills, but managers can improve over time with training programs.

The business school press has long advanced the optimal traits of managers based on case study analysis. But, generally, they are talking about company leaders, not lowerlevel managers. One study does identify boss traits based on a Gallup poll that asked 80,000 managers about their traits [10]. Unlike the case studies of Google and RBC, it does not attempt to quantify the impact of bosses on workers. Rather, it concludes that good bosses identify what is unique about each person and then try to capitalize on that. This conclusion seems to apply to all levels of managers.

Moving away from case studies and surveys, a very comprehensive empirical study of a large high-tech firm shows that managers with more people management skills-like coaching, training, and aligning the interests of the employee with those of the firm-have employees who are less likely to leave the firm [1]. Moreover, these top managers earn more and get promoted more. These results reinforce those from the earlier TBS study, which states that bosses should be teachers and should align the goals of the employee with those of the firm [2].

Senior-level executives have a performance lever that lower-level bosses do not: executives can choose their management "style." Economists have sought to quantify managers' identifiable approaches to managing. This was done in the aforementioned study of executives [5]. The authors show that managers have different "styles" of management. Those who focus on internal capital investments are less likely to undertake external investments like acquisitions. By contrast, those with an external focus invest less in 
R\&D. The authors proceed to show that styles are not better or worse, but are simply appropriate for each firm's environment. Young managers with an MBA are typically more aggressive managers (i.e. they make decisions faster, and consider fewer alternative points of view). There are also a series of articles showing, for manufacturing, that the management practices adopted by high-level managers affect workers' productivity [11], [12]. These practices include lean manufacturing methods and innovative human resource approaches such as new forms of incentive pay and careful hiring.

The above discussion implies that there are some universal traits that make a boss good, and other traits that differ across firms. The empirical studies that show bosses matter do not imply that a good boss at one firm would also be a good boss at another firm [2], [3]. In fact, the management strategy literature teaches that the human resource practices chosen by a firm should be tailored to fit the external strategy of the firm; in other words, not all firms should have the same practices [13]. Therefore, the traits or activities of bosses should differ across firms. At the CEO level, top managers often change firms and industries, so there must be some skills that are quite portable [5]. However, they also show that firms have different strategies, and that the executives hired to support these alternative strategies must have different skills. Turning to the lower-level bosses that are the focus of this article, the bosses of engineers at Google likely have some traits that differ from the traits of bosses of back-office workers at RBC. The inevitable conclusion is that common sense and some limited research suggests that there are some core traits of bosses that apply everywhere (teaching, coaching, being experts in the area, implementing the company's vision) and there are some that differ.

\section{Boss effects are greater than peer effects}

There is a growing literature showing that peers matter in the workplace and in the classroom. However, workplace data are scarce; most analysis is from school data, where peers are students and bosses are teachers and principals. In supermarket settings or lab settings, peers matter, but the effects are small [2]. In the grocery store, people work harder when someone is watching them do a simple task. But in the classroom or a dorm room, they are much more likely to share and learn from each other.

A question naturally arises from this research: as the firm is making hiring decisions, should it spend more time carefully screening workers or carefully screening bosses? The answer here is that they should spend more time on the screening of bosses to get high-quality bosses. In all likelihood, this is what firms now do; they spend more resources and time hiring a manager than hiring an individual worker. The research on boss effects reveals two reasons why. First, the variance of individual worker productivity explained by boss quality is much larger than that explained by worker quality or peer quality. The implication is that a bad boss has a greater effect on the distribution of worker productivity than a bad worker does. The second reason is that a boss affects a whole team of people simultaneously, often from ten to 30 people (with Google claiming large team sizes). Therefore, it is important to hire bosses with care, even though some managerial traits can be taught. 


\section{Workers quit bad bosses-Bad bosses leave the firm}

The saying is that "workers don't quit bad firms, they quit bad bosses." But what does the evidence support? The study of TBS jobs finds that workers do indeed quit more often when faced with bad bosses [2]. Google also found that employee retention rates are higher when the employee is supervised by a good boss [8]. Retention rates are likely higher because workers want the improved teaching and coaching that a good boss offers. Research also shows workers are happier with a good boss.

If bad bosses damage workers' performance and increase their turnover, should a bad boss not be pushed out by their superiors? In the TBS sector, they are: bosses who are in the lowest $10 \%$ of the quality distribution are over twice as likely to leave as those in the top $10 \%$ of the quality distribution [2]. Likewise, Google demotes poor bosses.

\section{LIMITATIONS AND GAPS}

Common sense suggests that many of the traits that make good bosses are universal: e.g. a good boss is someone who can teach well and is an expert in their field. However, more effort is needed to further explore these traits, particularly given the sizable role of bosses in the economy. In exploring the traits of children that cause them to earn more as adults, economists have shown that non-cognitive traits such as motivation and social skills can be as important as cognitive skills. Moreover, this literature explores at what age good traits are best taught, suggesting young children are better learners because habits become ingrained with age. The literature on bosses should also explore in more detail whether boss traits are innate or can be taught. There are likely to be some key traits that are needed to perform well as a boss. But ultimately, only a core portion of boss traits are likely to be universal: managing engineers is not the same as managing retail sales clerks.

A manager who seeks to be a top performer is surely given the advice to hire good people. Studies of performance improvements in schools identify the careful hiring and firing of teachers as a source of success for top principals [6]. Unfortunately, few studies that have employed data for managers and subordinates could identify the hiring patterns of managers. So it should be emphasized that the estimated performance effects of good bosses on workers do not permit bosses to hire better workers: these studies show that when workers move from a bad boss to a good boss they see their performance rise. Thus, while a portion of the performance gains induced by good bosses may include the careful hiring of workers, the focus has been on the effects of bosses on existing workers when bosses teach and coach the workers they have.

\section{SUMMARY AND POLICY ADVICE}

That bosses have a big impact on workers' performance is an important finding in the economics literature and has implications for how to manage firms optimally. Much of the existing literature focuses on the use of incentive pay, and often finds that incentives do increase performance. New research on bosses makes the following point: in circumstances where it may be hard to use incentive pay because it is hard to measure workers' performance, it may be just as valuable to assign workers to good bosses. Rather 
than investing in incentive pay for workers, firms can invest in the hiring and training of good bosses. Ongoing research is also focusing on the degree to which good bosses hire good workers, and supervise them well, and form good matches between the boss and the worker.

\section{Acknowledgments}

The author would like to thank an anonymous referee and the IZA World of Labor editors for many helpful suggestions on earlier drafts.

\section{Competing interests}

The IZA Word of Labor project is committed to the IZA Code of Conduct. The author declares to have observed the principles outlined in the code.

(c) Kathryn Shaw 


\section{REFERENCES}

\section{Further reading}

Gibbs, M., and E. Lazear. Personnel Economics in Practice. Hoboken, NJ: Wiley, 2015.

Ichniowski, C., and K. Shaw, "Beyond incentive pay: Insiders' estimates of the value of complementary human resource management practices." Journal of Economic Perspectives 17:1 (2003): $155-180$.

\section{Key references}

[1] Hoffman, M., and S. Tadelis. People Management Skills, Employee Attrition, and Manager Rewards: An Empirical Analysis. NBER Working Paper No. 24360, February 2018.

[2] Lazear, E., K. Shaw, and C. Stanton. "The value of bosses." Journal of Labor Economics 33:4 (2015): 823-862.

[3] Owan, H., T. Tsuru, and K. Uehara. "Seller-buyer ethnic matches: The case of car transactions at two North American auto dealerships." Hitotsubashi Journal of Economics 53:2 (2012): 217-236.

[4] Frederiksen, A., L. Kahn, and F. Lange. Supervisors and Performance Management Systems. NBER Working Paper No. 23351, April 2017.

[5] Bertrand, M., and A. Schoar. "Managing with style: The effect of managers on firm policies." Quarterly Journal of Economics 118:4 (2003): 1169-1208.

[6] Branch, G., E. Hanushek, and S. Rivkin. Estimating the Effect of Leaders on Public Sector Productivity: The Case of School Principals. NBER Working Paper No. 17803, February 2012.

[7] Goodall, A., L. Kahn, and A. Oswald. "Why do leaders matter? A study of expert knowledge in a superstar setting." Journal of Economic Behavior \& Organization 77:3 (2011): 265-284.

[8] Garvin, D., A. Wagonfeld, and L. Kind. "Google's Project Oxygen: Do managers matter?" Harvard Business School Case Study (2013).

[9] Schifrin, D., and K. Shaw. "Royal Bank of Canada: Transforming managers (A)." Stanford University Case No. HR42A (2015).

[10] Buckingham, M. "What great managers do." Harvard Business Review (2005).

[11] Ichniowski, C., K. Shaw, and G. Prennushi. "The effects of human resource management practices on productivity: A study of steel finishing lines." American Economic Review 87:3 (1997): 291-313.

[12] Bloom, N., and J. Van Reenen. "Measuring and explaining management practices across firms and countries." The Quarterly Journal of Economics 122:4 (2007): 1351-1408.

[13] Boning, B., C. Ichniowski, and K. Shaw. "Opportunity counts: Teams and the effectiveness of production incentives." Journal of Labor Economics 25:4 (2007): 613-650.

\section{Online extras}

The full reference list for this article is available from:

https://wol.iza.org/articles/bosses-matter-the-effects-of-managers-on-workers-performance

View the evidence map for this article:

https://wol.iza.org/articles/bosses-matter-the-effects-of-managers-on-workers-performance/map 